\title{
Irradiation alters the differentiation potential of bone marrow mesenchymal stem cells
}

\author{
YU WANG, GUOYING ZHU, JIANPING WANG and JUNXIANG CHEN \\ Department of Radiation Protection, Institute of Radiation Medicine, Fudan University, Shanghai 200032, P.R. China
}

Received March 20, 2015; Accepted October 7, 2015

DOI: $10.3892 / \mathrm{mmr} .2015 .4539$

\begin{abstract}
Bone injury following radiotherapy has been confirmed by epidemiological and animal studies. However, the underlying mechanism remains to be elucidated and no preventive or curative solution has been identified for this bone loss. The present study aimed to investigate the irradiation-altered osteogenesis and adipogenesis of bone marrow mesenchymal stem cells (BMSCs). BMSCs were derived and exposed to $\gamma$-irradiation at doses of $0,0.25$, $0.5,1,2,5$ and $10 \mathrm{~Gy}$. Cell viability was assessed using a 3-(4,5-dimethylthiazol-2-yl)-2,5 diphenyl tetrazolium bromide assay, and clonal expansion in vitro was detected by colony forming unit assessment. The osteogenic differentiation ability was demonstrated by alkaline phosphatase (ALP) activity, ALP staining and mineralization alizarin red staining, and the adipogenic differentiation ability was determined using Oil $\mathrm{O}$ red staining. The osteogenesis-associated genes, RUNX2, ALP, osteocalcin (OCN) and adipogenesis-associated genes, PPAR- $\gamma$ and $\mathrm{C} / \mathrm{EBP} \alpha$, were detected using reverse transcription-quantitative polymerase chain reaction analyses. The protein expression levels of RUNX2, ALP and PPAR- $\gamma$ were detected using western blotting. Compared with the control, significant decreases in the proliferation, ALP activity and mineralization ability of the BMSCs were observed in the $\gamma$-irradiation group, with a high level of correlation with the exposure dose. However, no significant changes were observed in the area of Oil red $\mathrm{O}$ positive staining. The mRNA levels of RUNX2, ALP and OCN were decreased $(\mathrm{P}<0.05)$, however, no significant changes were observed in the levels of $\mathrm{C} / \mathrm{EBP} \alpha$ and PPAR- $\gamma$. The protein expression levels of RUNX2 and ALP were decreased in the irradiated BMSCs, however, no significant difference was observed in the protein expression of PPAR- $\gamma$. Irradiation inhibited the osteogenic and adipogenic ability of the BMSCs, and the osteogenic differentiation was
\end{abstract}

Correspondence to: Mrs. Guoying Zhu, Department of Radiation Protection, Institute of Radiation Medicine, Fudan University, 2094 Xie-tu Road, Shanghai 200032, P.R. China

E-mail: zhugy@shmu.edu.cn

Key words: bone marrow mesenchymal stem cells, irradiation, osteogenesis, adipogenesis, differentiation decreased. The results of the present study provided evidence to assist in further elucidating radiotherapy-associated side effects on the skeleton.

\section{Introduction}

Radiation therapy is one of the most effective and indispensable treatment modalities for patients with cancer, and is used for the effective control of local disease and for palliative care (1). In a meta-analysis of individual patient data from 10,801 women in 17 randomized trials of radiotherapy following breast-conserving surgery, radiotherapy reduced the 10 year risk of any loco-regional or distant recurrence between 35.0 and $19.3 \%$, and reduced the 15 year risk of breast cancer-associated mortality between 25.2 and $21.4 \%$ (2). Improvements in cancer detection and treatment, and an aging population has resulted in increasing numbers of individuals living with and surviving from cancer. In the US, $64 \%$ of adults diagnosed with cancer are expected to survive at least 5 years (3), and the actuarial survival data of Indian patients with breast cancer with early stage disease at 10 years is $77 \%$ (4). However, the use of radiotherapy is often associated with normal tissue injury, which includes immediate and long-term damage to the normal tissues. Chronic side effects in survivors becomes a serious problem as the number of individuals treated and their expected survival rates increase (5). The skeletal system is one of the important targets for radiation-induced injury. Bone injury following radiotherapy has been confirmed in epidemiological and animal studies (6). A study involving 6,428 postmenopausal women who received radiotherapy showed that the risk of pelvic fractures was increased by $65-216 \%$ (7). Epidemiological studies have suggested that decreased bone mass is associated with increased adiposity with ageing, bone loss and osteoporosis (6). Skeletal complications following radiotherapy have also been reported in breast, pelvic, brain and blood cancer; with bone pain, pathological skeletal fracture, spinal cord compression, decreased survival rates and poor quality of life being reported (8-10).

Bone is one of the most commonly irradiated normal tissues, and the irradiation of bone can lead to multiple morbidities, including fracture and loss of marrow function (8). However, the underlying mechanism remains to be elucidated and no preventive or curative solution for this bone loss has been identified. Previous studies have suggested that radiotherapy is followed by bone loss, and is accompanied by increased fat 
content in bone marrow (9). Jia et al demonstrated that a single dose of radiation elicited a loss of bone mineral density (10). At a cellular level, osteoblasts and adipocytes arise from the same progenitor cells, bone marrow mesenchymal stem cells (BMSCs), which can differentiate into multiple cell lineages. Quantitative and qualitative stem cell defects may underlie the modified number and function of differentiated cells (11). Several previous studies have already examined hematopoietic recovery following irradiation, however, investigation into the bone marrow microenvironment has received less attention (12-15). Friedensteinand and Kuralesova first demonstrated that BMSCs exhibit high proliferation capacity and are able to form bone and cartilage (16). In addition, as BMSCs exhibit self-renewal, high proliferative and multiple differentiation potentials are crucial in bone recovery following irradiation, maintaining homeostasis with osteogenesis and adipogenesis under physiological conditions. The proliferation and growth are balanced with terminal differentiation, and this balance is essential for the modeling, growth and maintenance of the skeleton $(17,18)$. A previous study suggested that BMSCs maturation along the osteoblast lineage comes at the expense of adipogenesis, and vice versa, with aging (19). The observed inverse association between bone mass and fat mass in the bone marrow microenvironment has been hypothesized to be caused by enhanced differentiation of BMSCs into either the osteoblastic or adipocytic lineages at the expense of the alternative lineage (20). A study by Justesen et al supported the hypothesis that, with aging and in osteoporosis, enhanced adipogenesis is observed in the bone marrow, and that these changes are inversely correlated with decreased trabecular bone volume (21). However, other studies have found no evidence for enhanced adipogenesis with aging, finding that the adipocyte forming capacity of MSCs was similar in young and old donors $(22,23)$. The association between bone and fat formation within the bone marrow microenvironment is complex and remains an area of active investigation.

Modern radiation therapy aims to reduce side effects to a minimum. The ability of the patients to tolerate therapy is often determined by the potential of stem cells within the marrow to repair the damage resulting from ionizing radiation and to repopulate the marrow compartment (24). Therefore, it is important to investigate the effect of irradiation on the shift in differentiation between osteoblasts and adipocytes, and the possible underlying mechanism. The present study aimed to investigate the effect of irradiation on the proliferation and differentiation of BMSCs, particularly the effect of osteoblasts and adipocytes differentiation in vitro, to further elucidate irradiation induced bone loss disease and cell-based therapy.

\section{Materials and methods}

BMSC isolation and culture. The present study was reviewed and approved by the Committee for Ethical Use of Experimental Animals at Fudan University (Shanghai, China). The BMSCs were obtained from three male 2-4-week-old Sprague-Dawley rats (Department of Experimental Animals, Fudan University, Shanghai, China), which were housed at $20-26^{\circ} \mathrm{C}$ with a $16 \mathrm{~h}$ light and $8 \mathrm{~h}$ dark cycle, and provided ad libitum food and water. The rats were sacrificed by cervical dislocation and the animal skeleton was washed in $70 \%$ ethanol. The femurs and tibias were dissected, and muscle and connective tissue were removed. The end of the tibias and femurs were cut just below the end of the marrow cavity. A 27-gauge needle, attached to a $10 \mathrm{ml}$ syringe, containing complete media was inserted to flush the marrow plug out of the cut end of the bone into a dish. The cell suspension was added to $6 \mathrm{ml}$ Ficoll isolation (Shanghai Hua Jing Biological High Tech Co., Ltd., Shanghai, China) and centrifuged at $400 \mathrm{x} \mathrm{g}$ at $24^{\circ} \mathrm{C}$ for $30 \mathrm{~min}$. The cotton-like cells were collected at the interface, and were rinsed twice with $10 \%$ fetal bovine serum (FBS; Gibco; Thermo Fisher Scientific, Inc., Waltham, MA, USA) in low glucose Dulbecco's modified Eagle's medium (L-DMEM; GE Healthcare Life Sciences, Logan, UT, USA). The whole cells were resuspended in complete medium containing $10 \% \mathrm{FBS}$ and $100 \mathrm{U} / \mathrm{ml}$ penicillin/streptomycin (North China Pharmaceutical Co., Ltd., Shijiazhuang, China), and were seeded into a $25 \mathrm{~cm}^{2}$ flask for incubation at $37^{\circ} \mathrm{C}$ in a $5 \% \mathrm{CO}_{2}$ incubator. The non-adherent cells were removed after $2 \mathrm{~h}$ by replacing the medium with fresh complete medium. The medium was replaced every 3 days. On reaching a confluence of $80-90 \%$, the medium was discarded, and $0.5 \mathrm{ml}$ of $0.25 \%$ trypsin (Sigma-Aldrich, St. Louis, MO, USA)/1 mM ethylenediaminetetraacetic acid (China Pharmaceutical Shanghai Chemical Reagent Co., Ltd., Shanghai, China) was added for $2 \mathrm{~min}$ at room temperature. The trypsin was neutralized by adding complete medium. The harvested cells were cultured in a $25 \mathrm{~cm}^{2}$ flask $\left(\sim 1 \times 10^{6}\right.$ cells/ well) at a ratio of 1:2 (25).

Flow cytometry. BMSCs were characterized using flow cytometric analysis of cell surface markers (CD29, CD34, CD-44 and CD45). The cells after three passages (P3; 1X107 cells/ well) were trypsinized and washed with phosphate-buffered saline (PBS), and were subsequently resuspended in $0.5 \mathrm{ml}$ PBS. Rat polyclonal anti-CD34-fluorescein isothiocyanate (1:1,000; cat. no. bs-2038R; FITC; Bioss Biosynthesis Biotechnology Co., Ltd., Beijing, China), rat monoclonal anti-CD29-FITC (1:1,000; cat. no. 555005; BD Biosciences, San Jose, CA, USA), rat polyclonal anti-CD-44-FITC (1:1,000; cat. no. FAB6577G; R\&D Systems, Inc., Minneapolis, MN, USA) and rat anti-CD45-FITC (1:500; cat. no. 554877; BD Biosciences) antibodies were added separately, followed by $30 \mathrm{~min}$ incubation in the dark at $4^{\circ} \mathrm{C}$. The cells were rinsed twice in PBS at $200 \times \mathrm{g}$ for $5 \mathrm{~min}$, following which the cells were washed in $1 \mathrm{ml}$ PBS and analyzed using a flow cytometer (Gallios; Beckman Coulter, Brea, CA, USA). At least $1 \times 10^{5}$ cells were acquired and analyzed. Unstained cells were used as a control.

Differentiation assay. The $\mathrm{P} 3$ cells were trypsinized and seeded at a density of $5 \times 10^{4} / \mathrm{cm}^{2}$ into 48 well plates for each group. For osteogenic differentiation: The medium was replaced with induction medium after $48 \mathrm{~h}$. The osteogenic induction medium contained $10^{-8} \mathrm{~mol} / 1$ dexamethasone (Sigma-Aldrich), $10 \mathrm{mmol} / \mathrm{l} \beta$-glycerophosphate (China Pharmaceutical Shanghai Chemical Reagent Co., Ltd.), $50 \mu \mathrm{g} / \mathrm{ml}$ ascorbic acid (Sigma-Aldrich), $100 \mathrm{U} / \mathrm{ml}$ penicillin/streptomycin and $10 \%$ FBS in L-DMEM. The induction medium was replaced every 3 days. The osteogenic induction process was performed for 1 week $\left(37^{\circ} \mathrm{C} ; 5 \% \mathrm{CO}_{2}\right)$, and the process of was continued for 3 weeks $\left(37^{\circ} \mathrm{C} ; 5 \% \mathrm{CO}_{2}\right)$. The induction process 
Table I. Primers used in revers transcription-quantitative polymerase chain reaction analysis.

\begin{tabular}{lllc}
\hline Gene & \multicolumn{1}{c}{ Forward primer (5'-3') } & \multicolumn{1}{c}{ Reverse primer (3'-5') } & Product length (bp) \\
\hline ALP & CTGAGCGCACGCGAGCAAC & GGCGTGGTTCACCCGAGTGG & 116 \\
OCN & GAACAGACAAGTCCCACAC & GAGCTCACACACCTCCCTG & 270 \\
RUNX2 & TGCCACCTCTGACTTCTGC & GATGAAATGCCTGGGAACTG & 111 \\
PPAR- $\gamma$ & ACGGTTGATTTCTCCAGCAT & GGACGCAGGCTCTACTTTGA & 138 \\
C/EBP $\alpha$ & GGAGGGACTTAGGGAGTTGG & GGAAACCTGGCCTGTTGTAA & 146 \\
$\beta$-actin & CACCCGCGAGTACAACCTTC & CCCATACCCACCATCACACC & 207 \\
\hline
\end{tabular}

ALP, alkaline phosphatase; OCN, osteocalcin; RUNX-2, runt-related transcription factor 2; PPAR- $\gamma$, peroxisome proliferator-activated receptor- $\gamma ; \mathrm{C} / \mathrm{EBP} \alpha, \mathrm{CCAAT} /$ enhancer-binding protein $\alpha$.

of adipogenesis was performed by alternating between the induction medium, comprising $10^{-6} \mathrm{~mol} / \mathrm{l}$ dexamethasone, $0.5 \mathrm{mmol} / 1$ 3-isobutyl-1-methylxanthine (Sigma-Aldrich), $0.1 \mathrm{mmol} / 1$ indomethacin (Sigma-Aldrich), $100 \mathrm{U} / \mathrm{ml}$ penicillin and streptomycin and 10\% FBS L-DMEM, and the maintenance medium, comprising L-DMEM supplemented with $10 \mu \mathrm{g} / \mathrm{ml}$ insulin, $100 \mathrm{U} / \mathrm{ml}$ penicillin and streptomycin and $10 \%$ FBS, every 3 days. This process was continued for 2 weeks.

Irradiation and grouping. The samples were sorted into two groups, osteogenesis and adipogenesis. Each group of BMSCs was irradiated following a $24 \mathrm{~h}$ incubation using a ${ }^{137} \mathrm{Cs}$ gamma radiation source (Gammacell-40; MDS Nordion, Inc., Ontario, Canada) at a single dose.

Cell viability. The BMSCs were seeded into 96-well plates $\left(5 \times 10^{3}\right.$ cells/well $)$ and incubated in complete medium for $24 \mathrm{~h}$ $\left(37^{\circ} \mathrm{C} ; 5 \% \mathrm{CO}_{2}\right)$. The cells were exposed to various doses of irradiation $(0,0.25,0.5,1,2,5$ and $10 \mathrm{~Gy})$. The medium was subsequently removed and $100 \mu 1$ fresh L-DMEM containing $10 \%$ 3-(4, 5-dimethylthiazol-2-yl)-2,5-diphenyltetrazolium bromide (MTT) solution (Sigma-Aldrich; $0.5 \mathrm{mg} / \mathrm{ml}$ in PBS) was added into each well. Following $4 \mathrm{~h}$ incubation at $37^{\circ} \mathrm{C}$, the insoluble formazan crystals formed were dissolved in $100 \mu 110 \%$ sodium dodecyl sulfate (China Pharmaceutical Shanghai Chemical Reagent Co., Ltd.) for $2 \mathrm{~h}$. The optical density was immediately measured at $570 \mathrm{~nm}$ using a microplate reader (Multiskan fc reader; Thermo Fisher Scientific, Inc.).

Colony forming unit (CFU) assay. Cells in the exponential growth phase were trypsinized and made into a single cell suspension. The concentration of the cell suspension was adjusted to 200 cells $/ \mathrm{ml}$. A $5 \mathrm{ml}$ cell suspension was inoculated onto a petri dish (diameter $60 \mathrm{~mm}$ ), and the cells were evenly dispersed by gentle agitation of the dish in cross direction. The cells were exposed to different doses of irradiation $(0,0.5,1,2,5$ and $10 \mathrm{~Gy})$ after $24 \mathrm{~h}$. The culture was terminated after 2 weeks, when visible clones appeared in the petri dish. The cells were fixed with methanol for $15 \mathrm{~min}$. Giemsa staining (Amresco LLC, Solon, OH, USA) was performed for $10 \mathrm{~min}$ and observed by microscopy (Nikon 80i; Nikon Corporation, Tokyo, Japan) following air drying.
Cell cycle analysis. The cell cycle was detected using a Cell Cycle and Apoptosis Analysis kit (cat. no. C1052; Beyotime Institute of Biotechnology, Haimen, China) following doses of irradiation $(0,0.5,1,2,5$ or $10 \mathrm{~Gy})$. Briefly, the cells $\left(\sim 1 \mathrm{x} 10^{6}\right.$ cells) were trypsinized and made into a single cell suspension. The cells were subsequently fixed with pre-cooled $70 \%$ ethanol at $4^{\circ} \mathrm{C}$ for $12 \mathrm{~h}$, prior to incubating with propidium iodide solution $\left(5 \mu \mathrm{g} / \mathrm{ml}\right.$; Beyotime Institute of Biotechnology) at $37^{\circ} \mathrm{C}$ for $30 \mathrm{~min}$. Flow cytometric analysis was performed within $24 \mathrm{~h}$. DNA content and light scattering analyses were performed using software Navios $^{\mathrm{TM}}$; Beckman Counter).

Alkaline phosphatase (ALP) activity assay. The BMSCs were seeded into 96-well plates and were irradiated at different doses $(0,0.5,1,5$ or $10 \mathrm{~Gy})$ after $24 \mathrm{~h}$, following which the cells were cultured with osteogenic inductive medium for 7 and 14 days $\left(37^{\circ} \mathrm{C} ; 5 \% \mathrm{CO}_{2}\right)$. The measurement of ALP activity and protein content were performed, as described previously (26). Briefly, the cells were lysed with $0.05 \%$ Triton X-100 (Sigma-Aldrich) at $4^{\circ} \mathrm{C}$ for $2 \mathrm{~h}$, and were subsequently lysed by ultrasonication (VCX130PB Serial; Sonics \& Materials, Inc., Newtown, CT, USA) for $10 \mathrm{sec}$ at $20 \mathrm{kHz}$ three times on ice. A total of $50 \mu 1$ lysate was added to 2-amino-2-methyl-1-propanol buffer containing p-nitrophenyl phosphate (Fluka, Co, Milwaukee, WI, USA) at $37^{\circ} \mathrm{C}$ for $30 \mathrm{~min}$. The reactions were terminated by adding $50 \mu \mathrm{l} 0.2 \mathrm{~mol} / \mathrm{l} \mathrm{NaOH}$. The absorbance was detected at $405 \mathrm{~nm}$ using a Sunrise microplate reader (Thermo Fisher Scientific, Inc.). The total proteins were measured using a Bicinchoninic Acid kit (Beyotime Institute of Biotechnology), according to manufacturer's protocol. The activity was adjusted to the cell protein and expressed as U/mg protein.

ALP staining and Oil red $O$ staining. The BMSCs were cultured in 48 -well plates $\left(1 \times 10^{4}\right.$ cells/well) and irradiated after $24 \mathrm{~h}$. The cells were subsequently induced with osteogenic or adipogenic induction medium $\left(37^{\circ} \mathrm{C} ; 5 \% \mathrm{CO}_{2}\right)$. To estimate osteogenic differentiation, the cells were rinsed twice with PBS and fixed with $2.5 \%$ glutaraldehyde solution for $5 \mathrm{~min}$. The cells were subsequently stained using an ALP staining kit, according to the manufacturer's protocol (Tiangen Biotech Co., Lrd., Beijing, China). To estimate the adipogenic differentiation, the cells were fixed with $4 \%$ paraformaldehyde (Sigma-Aldrich) solution and rinsed with PBS. The cells were gently rinsed with $60 \%$ isopropanol and the 
stained with Oil Red O dye solution (Sigma-Aldrich) for $30 \mathrm{~min}$ at room temperature. Following staining, the cells were visualized and images were captured using an optical microscope (Nikon 80i). Simple PCI imaging software (Compix, Inc., Arizona, USA) was used to count the number and areas of positively stained cells.

Mineralization and alizarin red staining. The BMSCs were cultured in 48 -well plates $\left(5 \times 10^{4}\right.$ cells/well) and irradiated after $24 \mathrm{~h}$. Subsequently, the cells were induced with osteogenic inductive medium for 3 weeks $\left(37^{\circ} \mathrm{C} ; 5 \% \mathrm{CO}_{2}\right)$, and the medium was replaced every 2 days. The cells were fixed with $95 \%$ ethanol and rinsed with PBS. The cells were then stained with $0.2 \%$ alizarin red ( $\mathrm{pH} 8.3$; Amresco LLC) for $10 \mathrm{~min}$ at room temperature. The numbers and areas of mineralization nodules were quantified using an optical microscope (magnification, x100) and Simple PCI imaging software.

Reverse transcription-quantitative polymerase chain reaction (RT-qPCR) analysis. The BMSCs were seeded into 6-well plates at a density of $4 \times 10^{5}$ cells/well and were exposed to the different doses of irradiation after $24 \mathrm{~h}$. The cells were subsequently induced with osteogenic or adipogenic induction medium for 1 week. The total cellular RNA was isolated using an RNAprep pure cell/bacteria kit (Tiangen Biotech Co., Ltd.), according to the manufacturer's protocol. Subsequently, $1 \mu \mathrm{g}$ total RNA was transcribed into cDNA using a QuantScript RT kit (Tiangen Biotech Co., Ltd.), according to the manufacturer's protocol. All PCR primers were supplied by Sangon Biotech Co., Ltd. (Shanghai, China), and the primer sequences are listed in Table I. Specific transcripts were quantified by RT-qPCR using a QuantiTect $\mathrm{SYBR}^{\circledR}$ Green PCR kit (Takara Bio, Inc., Tokyo, Japan). A total of $2 \mu \mathrm{l}$ cDNA, $0.4 \mu \mathrm{l}$ primers, $10 \mu \mathrm{l} 2 \mathrm{X} \mathrm{SYBR}{ }^{\circledR}$ Premix

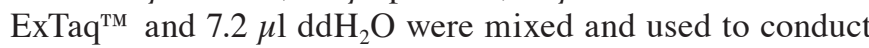
the reaction with a LightCycler 2.0 Real-Time PCR system (Roche Diagnostics GmbH, Mannheim, Germany). The $2^{-\Delta \Delta C q}$ method was used to calculate gene expression (27). The quantified individual RNA expression levels were normalized against $\beta$-actin. qPCR was performed as 40 cycles at $94^{\circ} \mathrm{C}$ for $15 \mathrm{sec}, 55^{\circ} \mathrm{C}$ for $30 \mathrm{sec}$ and $72^{\circ} \mathrm{C}$ for $30 \mathrm{sec}$. At least three independent experiments were performed.

Western blotting. The protein expression levels of PPAR- $\gamma$ and RUNX2 in the different groups were detected using western blot analysis. The cells were irradiated following incubation for $24 \mathrm{~h}$, and were induced for 2 weeks. The cells were lysed using $100 \mu \mathrm{l}$ radioimmunoprecipitation assay and $1 \mu \mathrm{l}$ phenylmethylsulfonyl fluoride (Beyotime Institute of Biotechnology). The samples were then centrifuged at $20,000 \mathrm{x} \mathrm{g}$ for $10 \mathrm{~min}$ at $4^{\circ} \mathrm{C}$. The supernatant were obtained and total protein concentration was measured using the Bicinchoninic Acid kit, according to manufacturer's protocol. Equal quantities of total protein $(20 \mu \mathrm{g})$ were subjected to sodium dodecyl sulfate polyacrylamide gel electrophoresis (5\% stacking gel and $12 \%$ separating gel; Beyotime Institute of Biotechnology) and transferred onto polyvinylidene fluoride membrane (Beyotime Institute of Biotechnology). The membrane was blocked with $5 \%(\mathrm{w} / \mathrm{v})$ non-fat milk dissolved in PBS-20\% Tween and, followed by incubation with rabbit anti-PPAR- $\gamma(1: 1,000$; cat. no. 07-466;
EMD Millipore, Billerica, MA, USA) and rabbit anti-RUNX2 (1:1,000; cat. no. 8486S; Cell Signaling Technology, Inc., Santa Cruz, CA, USA). The proteins were visualized by incubating the membrane with a secondary antibody conjugated to horseradish peroxidase. Tubulin (Beyotime Institute of Biotechnology) and GAPDH (Cell Signaling Technology, Inc.) were used as loading controls. The protein expression levels were quantified by the optical density ratio of the target protein and loading control using Quantity One ${ }^{\circledR}$ 4.6.3 software (Bio-Rad Laboratories, Inc., Hercules, CA, USA).

Statistical analysis. All data are expressed as the mean \pm standard deviation. One-way analysis of variance, followed by a least significant difference or Dunnett T3 test, was performed to compare means among multiple groups. Statistical analyses were performed using SPSS statistical software (IBM, SPSS, Chicago, IL, USA). P<0.05 was considered to indicate a statistically significant difference.

\section{Results}

Microscopic morphology and expression of surface makers in BMSCs. The BMSCs exhibited a fusiform projection, fibroblast-like, colony growth morphology. Cell surface marker analysis showed that the BMSCs were positive for CD29 (95.76\%) and CD44 (81.42\%), and negative for CD34 (12.70\%) and CD45 (26.56\%). Expression profiles of cell-surface markers are qualified as mesenchymal stem cells (28) (Fig. 1).

Cell viability. The cell growth curve showed that the cells exhibited a sustained proliferation state, and entered the logarithmic phase after 3 days in culture (Fig. 2). The proliferation rate of the BMSCs was maintained at a high level, even after 14 days in culture $\left(37^{\circ} \mathrm{C} ; 5 \% \mathrm{CO}_{2}\right)$. No significant difference was observed following 9 days of culture with basic culture medium. Cell viability was marginally lower when cultured for 11 days with induction medium, however, the difference was not significant. Therefore, the adipogenic or osteogenic induction medium had no affect on the cell viability, compared with the basic culture medium $(\mathrm{P}>0.05)$, enabling examination of the differences between groups without the requirement to consider the inference of induction medium in the following experiments.

An MTT assay was performed to identify the viability of the BMSCs following different doses of irradiation. The results showed that the viability of the BMSCs decreased with increasing dose. Irradiation at 5 Gy significantly suppressed the cell viability $(\mathrm{P}<0.05)$, and cell viability was decreased further following exposure to $10 \mathrm{~Gy}$ irradiation (Fig. 3).

Cell differentiation. The BMSCs were directly induced to form osteoblasts in osteogenic induction medium for 7 days. A marked increase in the number of ALP-positively stained cells was observed, compared with the non-induced BMSCs. Mineralized nodules formed following osteogenic induction for 21 days, whereas no mineralized nodules were observed in the non-induced cells. The Oil red O staining assay showed that lipid droplets were generated following adipogenic induction for 14 days (Fig. 2). 
Table II. Effect of different doses of irradiation on ALP activity following 7 days of osteogenic induction.

\begin{tabular}{lcr}
\hline Irradiation dose $(\mathrm{Gy})$ & ALP activity (U/mg protein) & Change in ALP activity (\%) \\
\hline 0 & $81.500 \pm 5.788$ & - \\
0.5 & $73.992 \pm 4.174^{\mathrm{a}}$ & $\downarrow 9.21$ \\
1 & $56.294 \pm 4.983^{\mathrm{a}}$ & $\downarrow 30.93$ \\
5 & $43.850 \pm 2.560^{\mathrm{a}}$ & $\downarrow 46.20$ \\
10 & $39.832 \pm 1.520^{\mathrm{a}}$ & $\downarrow 51.13$
\end{tabular}

Values are expressed as the mean \pm standard deviation of three independent experiments. ${ }^{\text {a }}<0.05$, compared with the 0 Gy group. ALP, alkaline phosphatase.
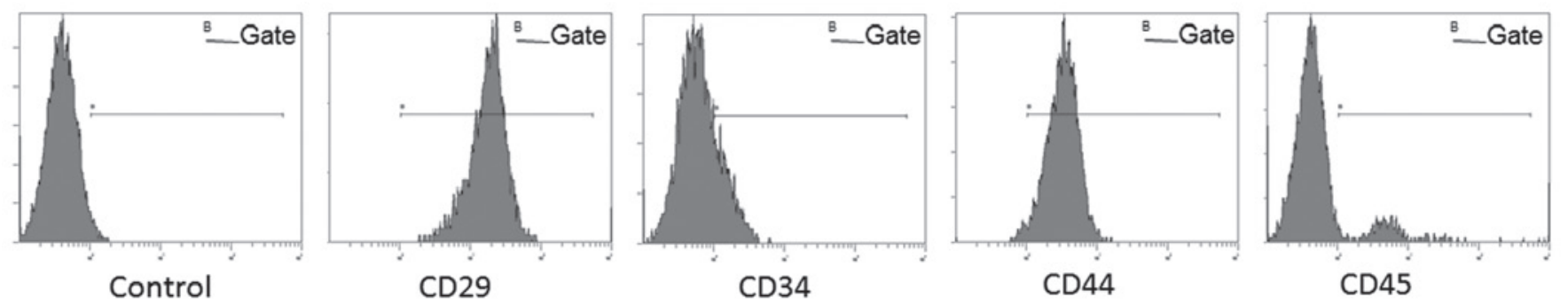

Figure 1. Expression of surface markers in bone marrow mesenchymal stem cells.

CFU assay. The results of the CFU assay showed that the cells exhibited a high colony formation rate $(89.67 \%$ in the non-irradiation group) in vitro. As shown by Giemsa staining, the numbers of cells in each colony were reduced following irradiation (Fig. 4). The number of CFUs reduced as the irradiation dose was increased for the same duration. Irradiation at $0.5 \mathrm{~Gy}$ significantly reduced the colony formation potential of the BMSCs $(\mathrm{P}<0.05$; Fig. 4).

Cell cycle distribution. The results of the present study revealed that BMSC were predominantly in the G0 stage of the cell cycle. Irradiation failed to alter the cell cycle, which suggests that changes in cell proliferation are not achieved through the alteration of cell cycle progression (Fig. 5).

ALP activity following irradiation. The effect of different doses of irradiation on ALP activity was determined following 7 days osteogenic induction. The results showed that all doses $(0.5,1,5$ and $10 \mathrm{~Gy})$ of irradiation decreased ALP activity $(\mathrm{P}<0.05)$, compared with the control group. Additionally, the ALP activity decreased with increasing irradiation dose (Table II).

$A L P$ and Oil red $O$ staining. Visualization of the cells under an optical microscope revealed that both the size of the stained area and color density decreased as irradiation dose increased. The surface area of positive ALP staining decreased with increasing irradiation dose. Irradiation at 0.25 Gy significantly suppressed positive ALP staining $(\mathrm{P}<0.05$; Fig. 6).

The results of the present study demonstrated that the rate of positive Oil Red O staining increased marginally following $0.25,0.5$ or $1 \mathrm{~Gy}$ irradiation, and decreased following 2 or $5 \mathrm{~Gy}$ irradiation, although no statistical difference was observed (P>0.05; Fig. 7). These results indicated that the adipogenic differentiation potential of the BMSCs was not markedly altered following irradiation.

Mineralization and alizarin red staining. As shown in Fig. 7, the alizarin red staining of mineralization showed that $\gamma$-irradiation reduced mineralization abilities in vitro. Quantification of the ARS deposition areas revealed that irradiation suppressed the mineralization of osteogenesis at all irradiation doses (Fig. 8).

$R T$ - $q P C R$ analysis. The present study revealed that the mRNA expression levels of ALP, RUNX2 and OCN were reduced following $0.5 \mathrm{~Gy}$ irradiation $(\mathrm{P}<0.05)$, compared with the non-irradiated group. The expression levels of ALP, RUNX2 and $\mathrm{OCN}$ were significantly decreased with increasing irradiation dose (Fig. 9). The mRNA expression levels of PPAR- $\gamma$ and $\mathrm{CEBP} \alpha$ were not significantly altered following irradiation (Fig. 10).

Western blotting. The protein expression levels of RUNX2 and PPAR- $\gamma$ were detected using western blotting. As shown in Fig. 10, the protein expression of RUNX2 decreased with increased irradiation dose $(\mathrm{P}<0.05)$, whereas the protein expression of PPAR- $\gamma$ was not significantly altered by irradiation $(\mathrm{P}>0.05$; Fig. 11).

\section{Discussion}

Osteoporosis and fracture are late effects of radiotherapy, and present as bone loss, decreased bone strength and increased fracture rate in cancer survivors, with unknown etiology 
A
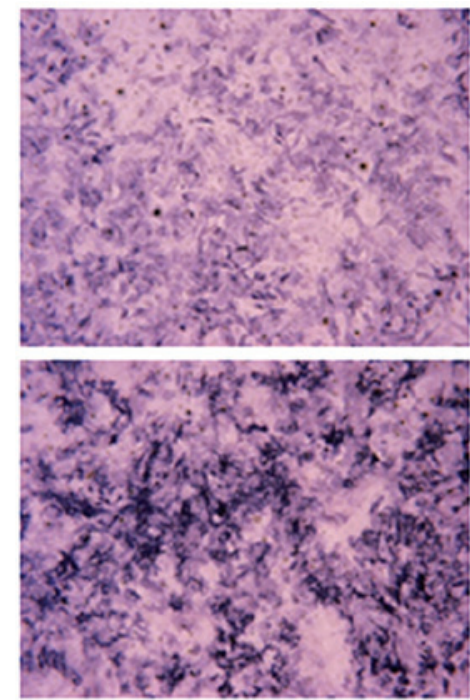

B
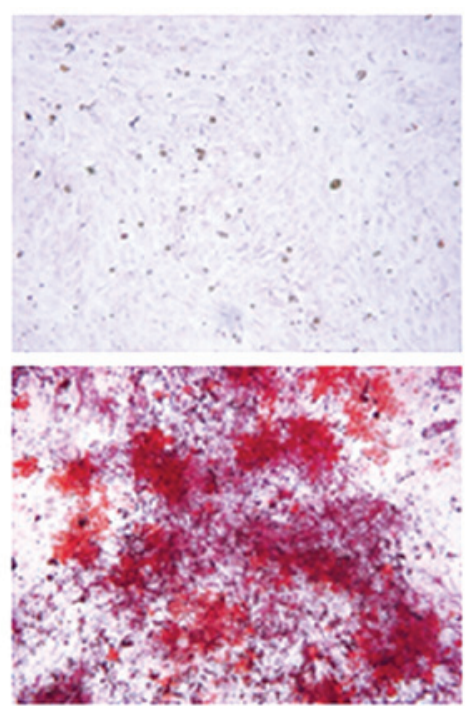

C
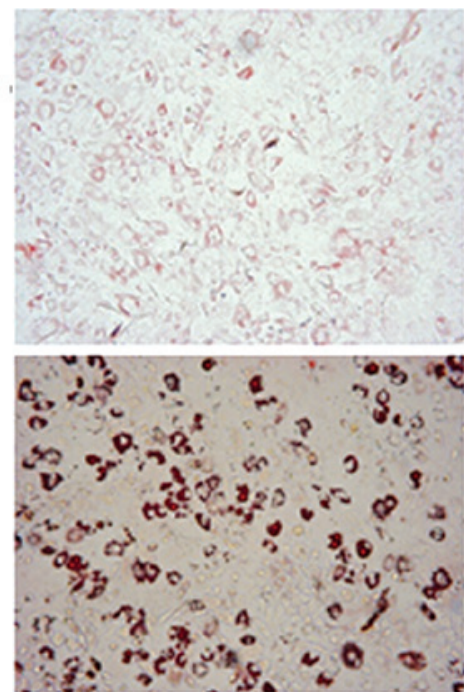

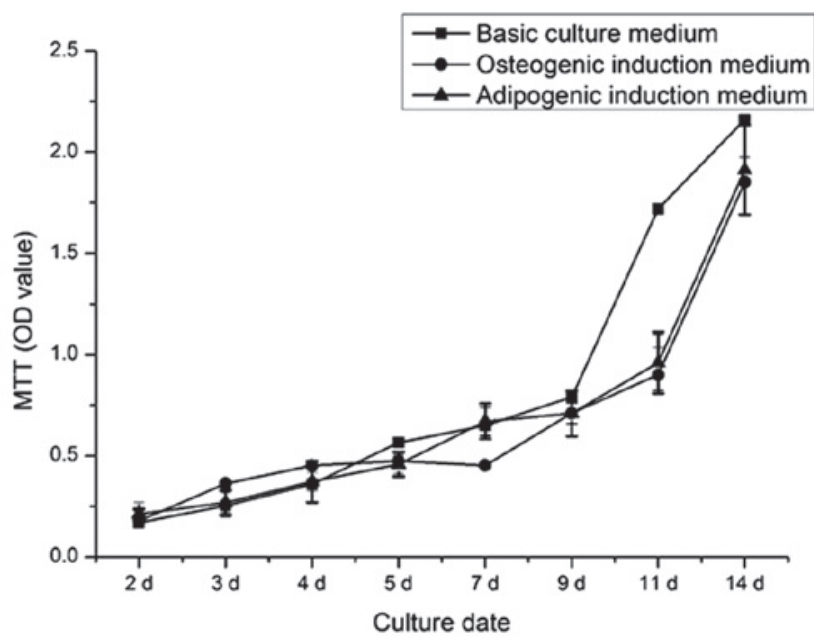

Figure 2. BMSC induction and the viability of BMSCs cultured with different culture medium over time. (A) Upper panel, ALP staining of non-induced cultured BMSCs for 7 days (original magnification, x40); lower panel, ALP staining of osteogenic induction of BMSCs for 7 days (original magnification, x40). Dark blue granules indicate ALP staining. (B) Upper panel, ARS staining of non-induced cells after 21 days (original magnification, x100); lower panel, ARS staining of mineralized nodules following osteogenic induction of BMSCs for 21 days (original magnification, x100). Mineralized nodules stained red. (C) Upper panel, Oil Red O staining of non-induced BMSCs after 14 days (magnification, x200); lower panel, Oil Red O staining of adipogenic induction of BMSCs for 14 days (magnification, x200). Fat droplets stained red. Data are expressed as the mean \pm standard deviation. BMSC, bone marrow mesenchymal stem cell; ALP, alkaline phosphatase; ARS, alizarin red S; MTT, 3-(4,5-dimethylthiazol-2-yl)-2, 5-diphenyltetrazolium bromide; OD, optical density.

and lack of treatment options. A previous study revealed that radiation can result in loss of trabecular bone (29). Increased trabecular thickness and separation, and reduced cancellous bone volume fraction, connectivity density and trabecular number were detected in the proximal tibia and lumbar vertebra 14 days following 6 Gy $\gamma$-irradiation (30). Thus, irradiation exposure leads to the destruction of bone architecture, thereby increasing an individuals lifetime risk of bone loss and fracture.

In bone healing or distraction osteogenesis, progenitor cells are involved through successive formation of fibrous, cartilaginous and osseous tissues (31). BMSCs are considered as the most suitable cell source for bone tissue engineering due to their superior osteogenic potential. Adipocytes and osteoblasts originate from BMSCs, and the balance between adipogenesis and osteogenesis in BMSCs is reported to modulate the progression of various diseases, including obesity and osteoporosis (32). The high proliferative capacity of BMSCs

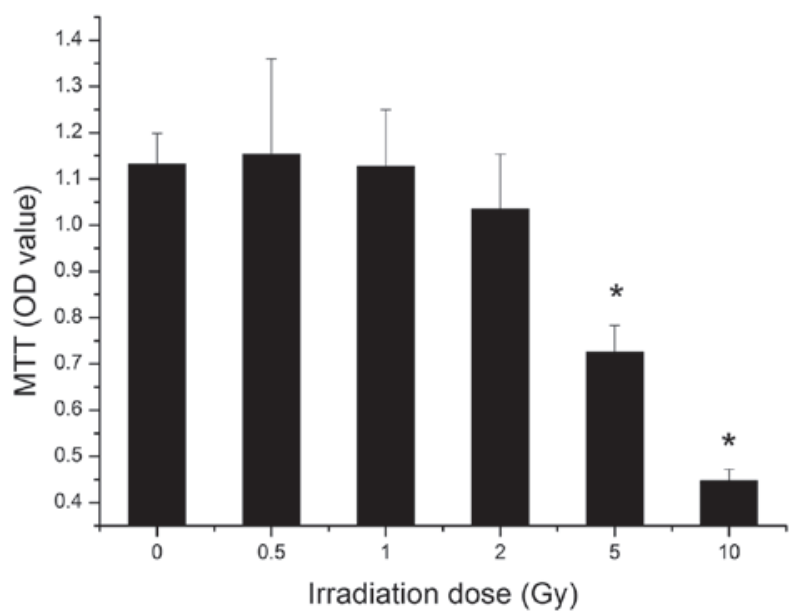

Figure 3. Changes in cell viability following irradiation. Data are expressed as the mean \pm standard deviation and are representative of three separate experiments. ${ }^{*} \mathrm{P}<0.05$, compared with the 0 Gy group. MTT, 3-(4,5-dimethylthiazol-2-yl)-2, 5-diphenyltetrazolium bromide; OD, optical density. 
A

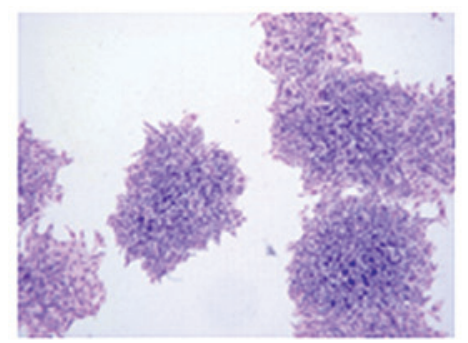

D

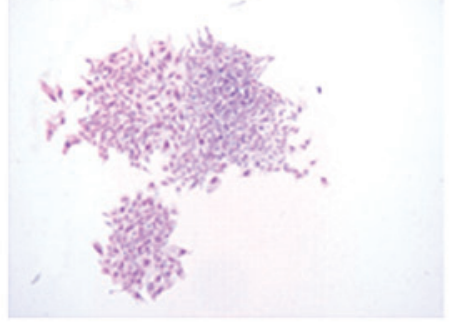

B

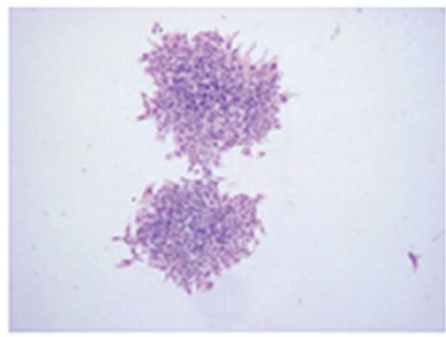

$\mathbf{E}$

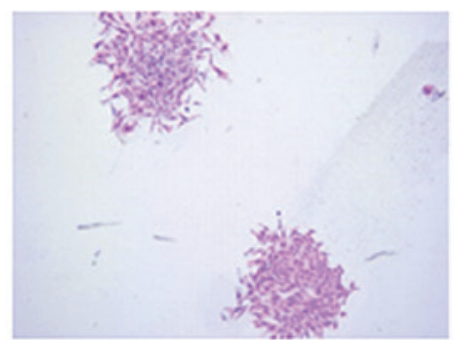

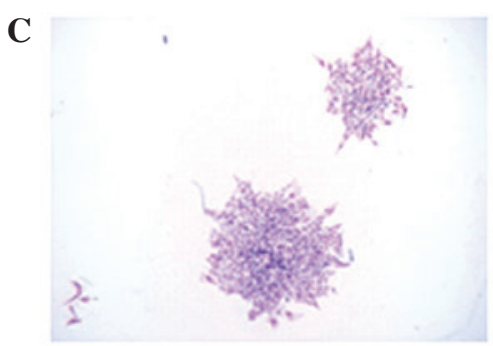

F

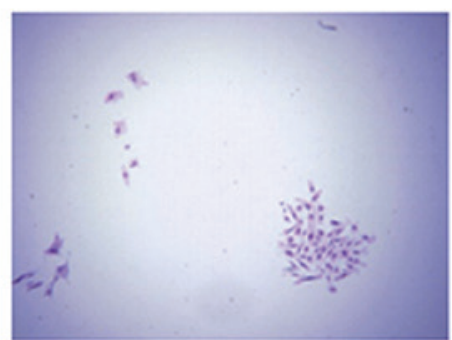

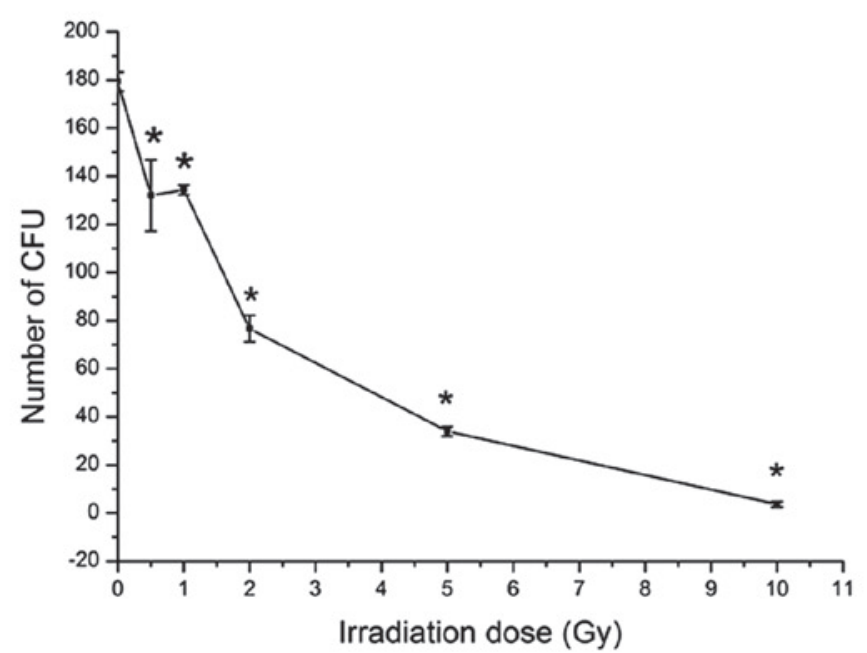

Figure 4. CFUs of BMSCs following irradiation. Giemsa staining of the BMSCs following irradiation at (A) 0 Gy, (B) 0.5 Gy, (C) 1 Gy, (D) 2 Gy, (E) 5 Gy, (F) 10 Gy. Original magnification, $x 20$. The graph shows the number of CFUs following irradiation with doses of 0, 0.5, 1,2,5 and 10 Gy. Data are expressed as the mean \pm standard deviation " $\mathrm{P}<0.05$, compared with the 0 Gy group. BMSC, bone marrow mesenchymal stem cell; CFU, colony-forming unit.

makes them susceptible to damage and injury, altering the steady-state of the bone marrow environment.

Differentiation into osteoblast and adipocyte lineages has particular relevance to the maintenance of normal bone homeostasis. Irradiation can damage the osteogenic activity of human marrow by suppressing osteoblasts, leading to post-irradiation bone loss and osteoporosis (33). However, the role of irradiation in modulating the adipogenic and osteogenic potential remains to be elucidated.

For over a decade, it has been hypothesized that an inverse association exists between adipocytes and osteoblasts within the marrow cavity (34). Despite substantial data supporting the adverse association between osteoblasts and adipocytes, studies revealed a more complex association between bone and fat tissue volume in human and animal models in vivo (35).

The present study hypothesized that radiation therapy alters the osteogenic and adipogenic differentiation potentials of BMSCs. To confirm this hypothesis, the Ficoll technique was used to isolate cells, as a previous study suggested that the Ficoll technique may be suitable for the isolation of multi-potent BMSCs (36). The cells obtained exhibited high proliferation potential under basic culture medium and in induction medium, and the cell surface makers were suitable for qualification as stem cells. Following induction, BMSCs can successfully differentiate into osteoblasts and adipocytes in vitro.

The results of the present study demonstrated that 2 Gy irradiation reduced cell viability. This was concordant with a previous study, which demonstrated that persistent injury in the stem cell population can be induced by relatively small doses, and that the threshold total dose in mice is $\sim 1.5 \mathrm{~Gy}$, determined using fractionated whole-body irradiation (37). The CFU assay in the present study showed that $0.5 \mathrm{~Gy}$ irradiation decreased cell proliferation, suggesting that the BMSCs were relatively sensitive to irradiation in vivo or in vitro.

Normal cells are permanently held in a state in which their continued existence depends on a tight balance between survival and death signals. In a normal cell, the accumulation of DNA damage leads to cell cycle arrest, during which the potential for repair is assessed. If the extent of the damage exceeds the capacity to repair without leaving residual genetic abnormality, the balance of survival and death signals tips, and the cell activates its apoptotic signaling pathway leading to cell death (38). The results of the present study showed 
A

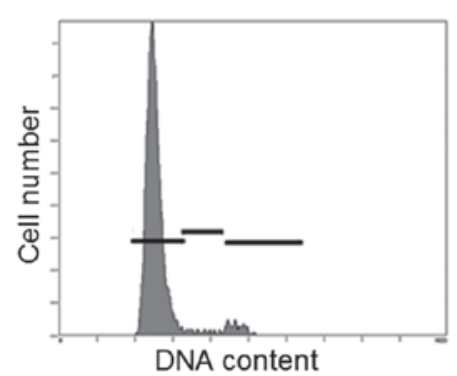

D

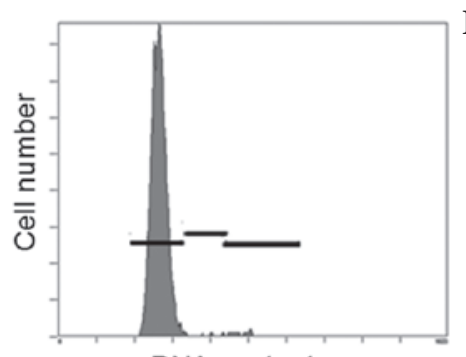

DNA content

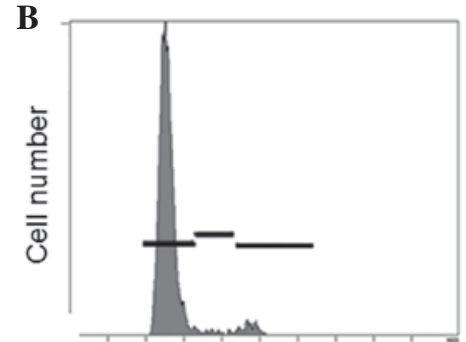

DNA content

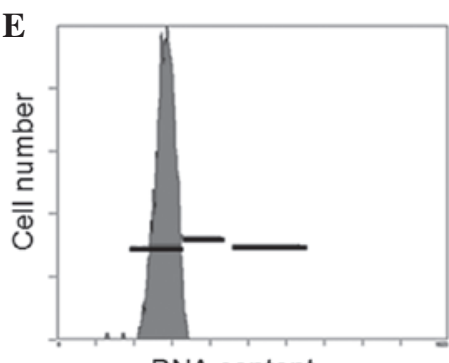

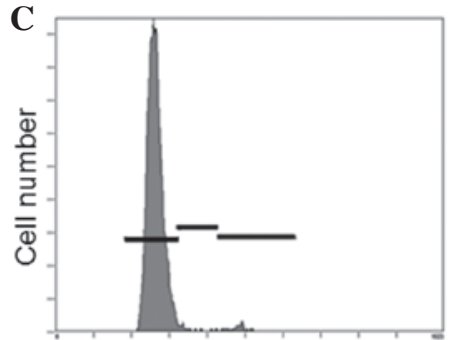

DNA content

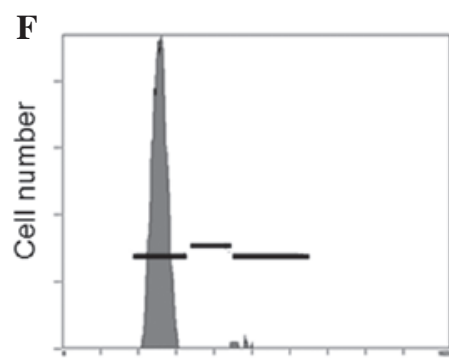

DNA content

Figure 5. Cell cycle distribution of bone marrow mesenchymal stem cells following irradiation. Cell cycle distribution was analyzed using flow cytometric analysis following irradiation doses of (A) $0 \mathrm{~Gy}$; (B) $0.5 \mathrm{~Gy}$; (C) $1 \mathrm{~Gy}$; (D) $2 \mathrm{~Gy}$; (E) $5 \mathrm{~Gy}$; (F) $10 \mathrm{~Gy}$. The lines in each image represent the $\mathrm{G}_{0} / \mathrm{G}_{1}, \mathrm{~S}$, and $\mathrm{G}_{2} / \mathrm{M}$ cell cycle stages (from left to right) of the bone marrow mesenchymal stem cells. Cells of each group were predominantly in the $\mathrm{G}_{0}$ stage of the cell cycle.

A
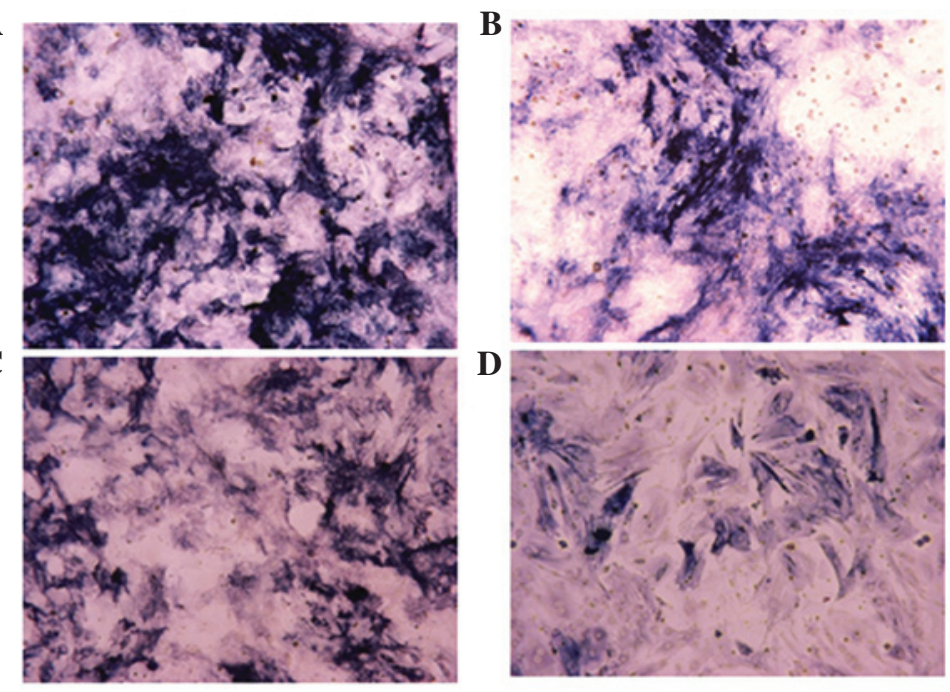

D
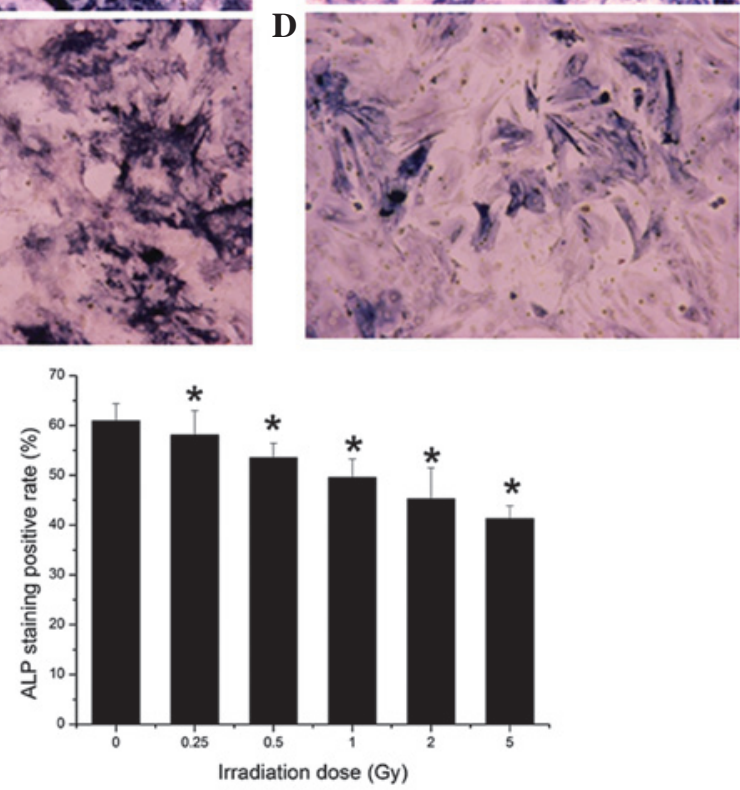

Figure 6. ALP staining following irradiation of different doses. (A) 0 Gy; (B) 0.5 Gy; (C) 1 Gy; (D) 5 Gy. Original magnification, x 100 . The graph shows the positive rate of ALP staining following irradiation at $0,0.5,1,5$ and $10 \mathrm{~Gy}$. Both the size of the stained area and color density of ALP staining decreased as irradiation dose increased. Data are expressed as the mean \pm standard deviation. ${ }^{*} \mathrm{P}<0.05$, compared with the 0 Gy group. ALP, alkaline phosphatase.

no significant cell cycle arrest following different dose of irradiation, therefore further investigation of the mechanism is required.
The results of the ALP and Oil red O staining assay indicated that irradiation may have a suppressive effect on osteogenic differentiation of the BMSCs, however, it had 
A
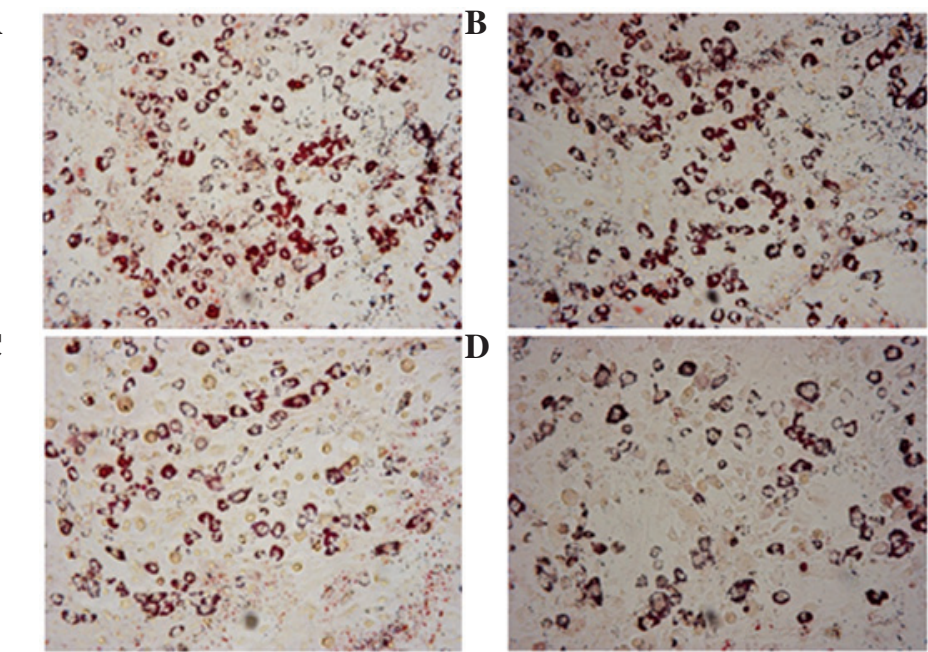

D
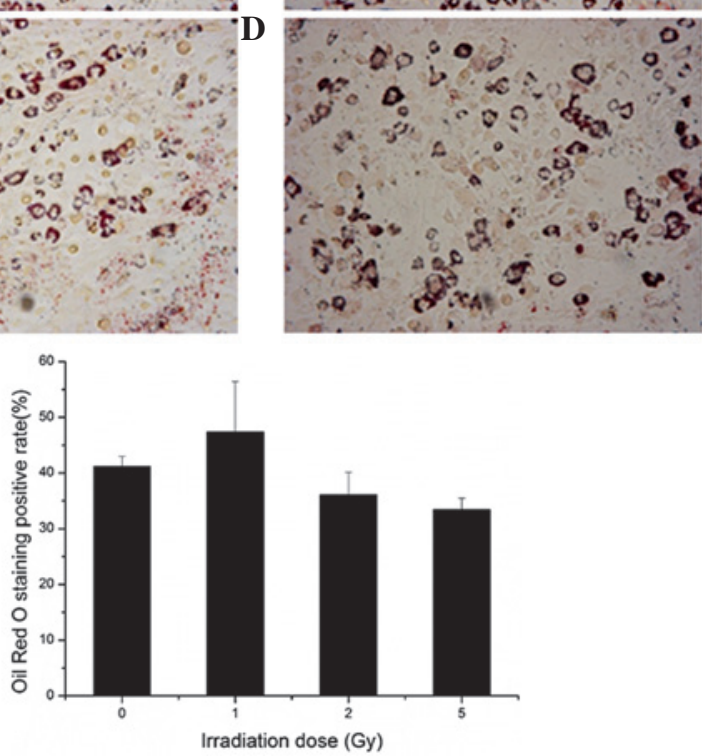

Figure 7. Oil red O staining following irradiation of different doses. (A) 0 Gy; (B) 1 Gy; (C) 2 Gy; and (D) 5 Gy. Original magnification, x200. The graph shows the positive rate of ALP staining following irradiation at $0,1,2$ and $5 \mathrm{~Gy}$. The rate of positive Oil Red $\mathrm{O}$ staining was not markedly altered following irradiation. Data are expressed as the mean \pm standard deviation. ALP, alkaline phosphatase.

A

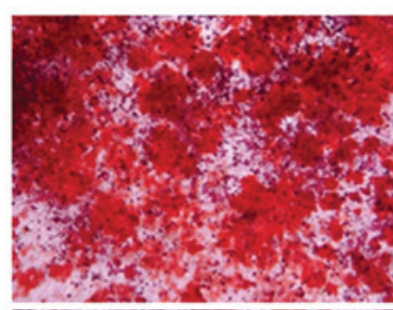

C
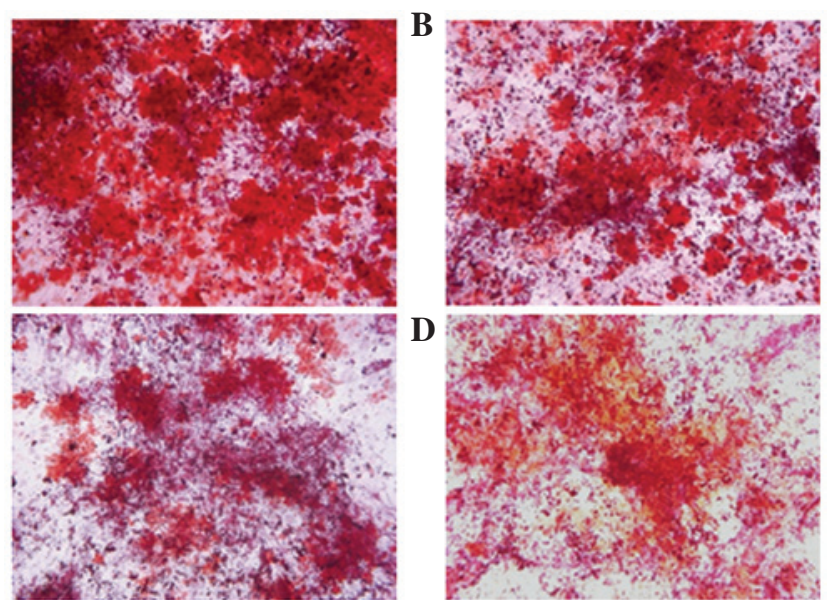

D
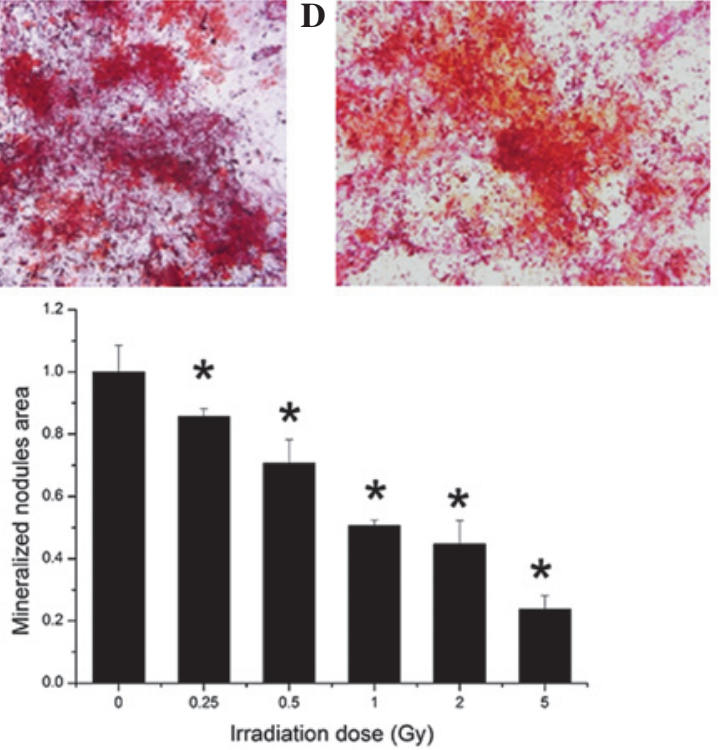

Figure 8. ARS staining of mineralized nodules following irradiation at doses of (A) 0 Gy, (B) $0.5 \mathrm{~Gy}$, (C) 1 Gy and (D) 5 Gy. Original magnification, x100. The chart shows the quantification of ARS deposition areas following irradiation at $0,0.25,0.5,1,2$ and 5 Gy. Both the size of the stained area and color density of ARS staining decreased as irradiation dose increased. Data are expressed as the mean \pm standard deviation. ${ }^{*} \mathrm{P}<0.05$, compared with the 0 Gy group. ARS, alizarin red $\mathrm{S}$. 


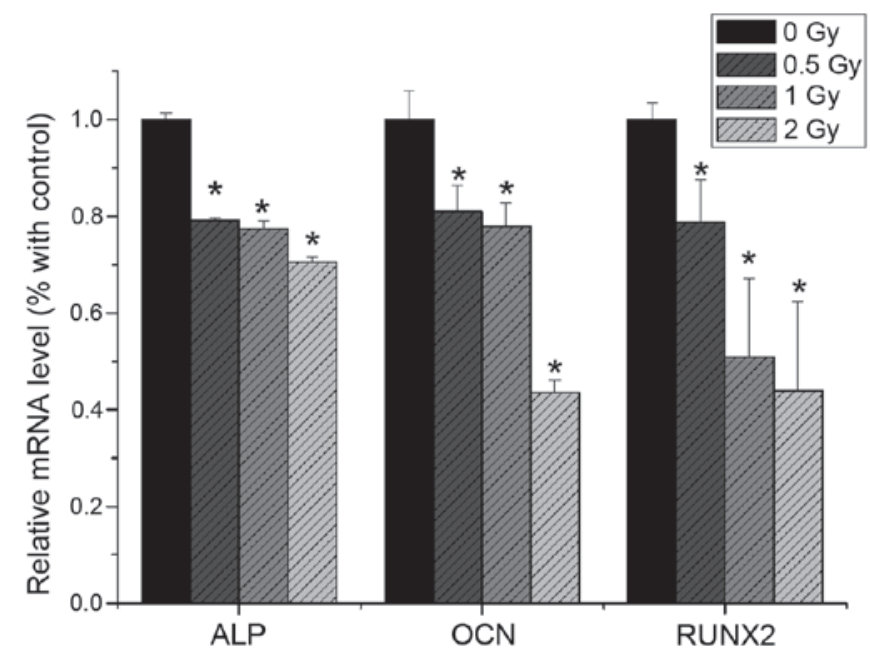

Figure 9. mRNA expression levels of ALP, OCN and RUNX2 for induction following irradiation (doses at 0,0.5, 1 and $2 \mathrm{~Gy}$ ). Data are expressed as the mean \pm standard deviation. ${ }^{*} \mathrm{P}<0.05$, compared with the 0 Gy group $(n=3)$. ALP, alkaline phosphatase; OCN, osteocalcin; RUNX2, Runt-related transcription factor 2 .

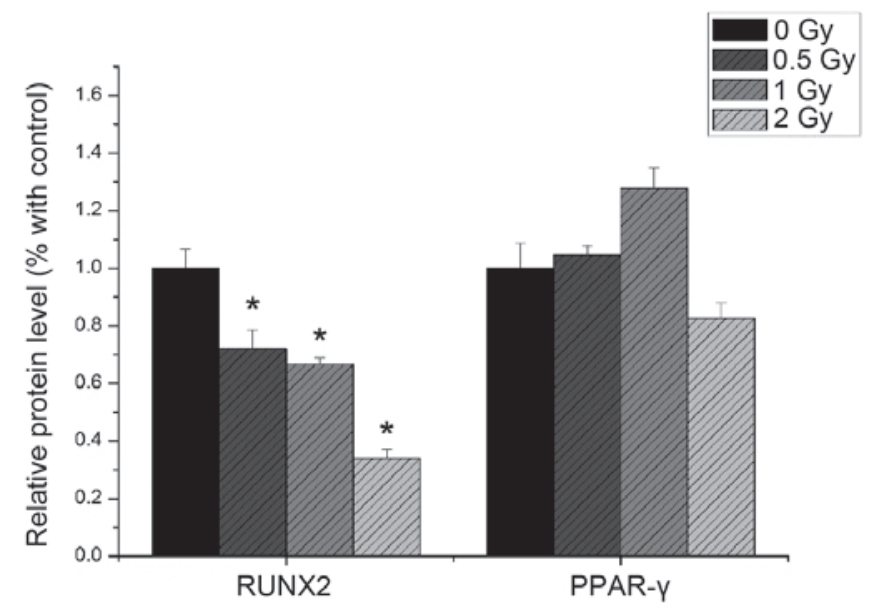

Figure 10. mRNA expression levels of PPAR- $\gamma$ and CEBP $\alpha$ for induction following irradiation (doses at $0,0.5,1$ and $2 \mathrm{~Gy}$ ). Data are expressed as the mean \pm standard deviation. ${ }^{*} \mathrm{P}>0.05$, compared with the 0 Gy group $(n=3)$. PPAR- $\gamma$, peroxisome proliferator-activated receptor- $\gamma$; CEBP $\alpha$, CCAAT/enhancer-binding protein $\alpha$.

no marked suppressive or enhancing effect on adipogenic differentiation. However, the relative ratio of osteogenesis and adipogenesis was increased, therefore, further examination of the gene and protein expression levels in the process of BMSCs differentiation was performed.

The developmental fate of BMSCs is largely determined by the expression of specific groups of transcription factors to drive the differentiation of uncommitted precursors down a specific lineage. Expression of the RUNX2 and osterix transcription factors are the predominant determinants for the osteogenic differentiation of BMSCs (39). In addition, the peroxisome proliferator activated receptor- $\gamma$ (PPAR- $\gamma$ ) transcription factor and the CCAAT/enhancer-binding protein family, are key factors driving the adipogenesis differentiation of BMSCs (40). In the present study, the expression levels of RUNX2, ALP and OCN were decreased following irradiation,

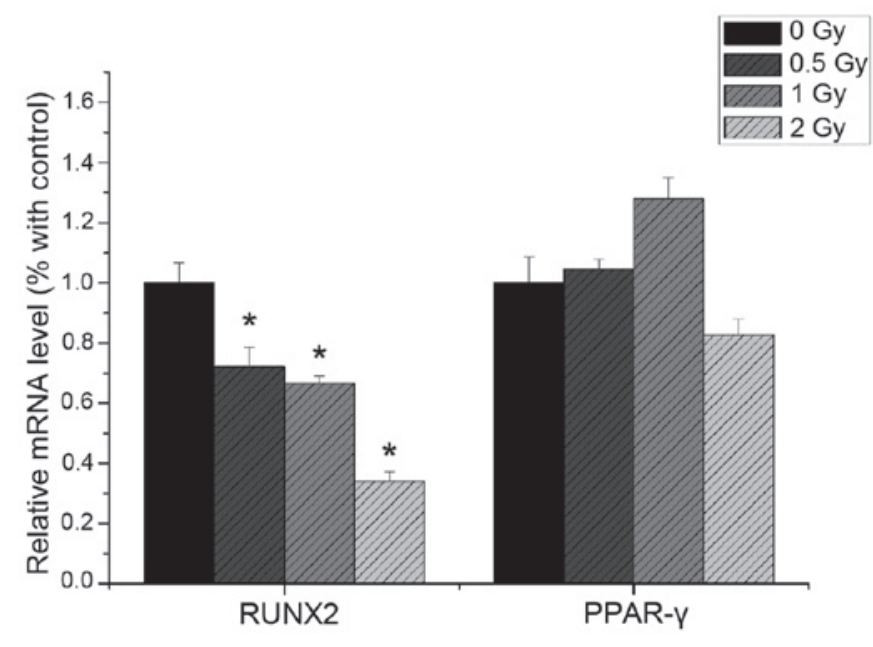

Figure 11. Protein expression levels of RUNX2 and PPAR- $\gamma$ detected by western blotting. Expression levels were detected following irradiation at doses of $0,0.5,1$ and $2 \mathrm{~Gy}$. Data are expressed as the mean \pm standard deviation. ${ }^{*} \mathrm{P}<0.05$, compared with the 0 Gy group $(n=3)$. PPAR $-\gamma$, peroxisome proliferator-activated receptor- $\gamma$; RUNX2, runt-related transcription factor 2 .

indicating that irradiation suppressed osteogenic differentiation at the early and late stages of differentiation. Therefore, the proliferation of pre-osteoblasts and the formation of osteoid were inhibited, as regulated by the osteogenic differentiation of BMSCs, resulting in an imbalance of bone formation.

PPAR- $\gamma$, also termed the glitazone receptor or 7nuclear receptor subfamily 1 , group $\mathrm{C}$, member 3 , is a ligand-activated transcription factor, which belongs to the type II nuclear hormone receptor superfamily and functions as a heterodimer with a retinoid $X$ receptor by binding to PPAR- $\gamma$ responsive elements. PPAR $-\gamma$ is important in adipocyte differentiation. Adipogenesis commitment of MSCs is determined by the expression and/or activation of the PPAR- $\gamma$ transcription factor (41). In the present study, no significant changes in the gene and protein expression levels of PPAR- $\gamma$ were observed following irradiation. Therefore, the present study does not support the hypothesis that decreased bone volume and increased adipose tissue following radiotherapy is the result of irradiation-induced alterations in the cellular compositions of osteoblasts and adipocytes in BMSCs. Although these results differ from the results of previous studies, certain studies support the results of the present study. For example, Justesen et al (42) reported no evidence for enhanced adipogenesis with aging, as the adipocyte forming capacity of BMSCs was similar between younger and older donors (42).

A possible explanation of the results of the present study is that adipogenesis and osteogenesis can be regulated independently. In support of this hypothesis, further experiments are required to demonstrate the specific mechanisms of lipid metabolism and bone metabolism.

Bone marrow post-irradiation syndrome seriously affects quality of life in individuals following tumor treatment. Therefore, investigating the mechanisms underlying bone injury and recovery can provide novel insights into MSC differentiation and the treatment of bone loss diseases to reduce the risk of fracture. 


\section{Acknowledgements}

The present study was sponsored by the Shanghai Natural Science Fund (grant no. 14ZR1401600) and Shanghai Municipal Commission of Health (grant no. 2013ZYJB0801).

\section{References}

1. Jeremic B: Radiation therapy. Hematol Oncol Clin North Am 18: 1-12, 2004.

2. Darby S, McGale P, Correa C, Taylor C, Arriagada R, Clarke M, Cutter D, Davies C, Ewertz M, Godwin J, et al; Early Breast Cancer Trialists' Collaborative Group (EBCTCG): Effect of radiotherapy after breast-conserving surgery on 10-year recurrence and 15-year breast cancer death: Meta-analysis of individual patient data for 10,801 women in 17 randomised trials. Lancet 378: 1707-1716, 2011.

3. Cancer survivorship - United States, 1971-2001. MMWR Morb Mortal Wkly Rep 53: 526-529, 2004.

4. Dinshaw KA, Budrukkar AN, Chinoy RF, Sarin R, Badwe R, Hawaldar R and Shrivastava SK: Profile of prognostic factors in 1022 Indian women with early-stage breast cancer treated with breast-conserving therapy. Int J Radiat Oncol Biol Phys 63: 1132-1141, 2005.

5. Agrawal S: Late effects of cancer treatment in breast cancer survivors. South Asian J Cancer 3: 112-115, 2014.

6. Williams HJ and Davies AM: The effect of X-rays on bone: A pictorial review. Eur Radiol 16: 619-633, 2006.

7. Baxter NN, Habermann EB, Tepper JE, Durham SB and Virnig BA: Risk of pelvic fractures in older women following pelvic irradiation. JAMA 294: 2587-2593, 2005.

8. Green DE, Rubin CT: Consequences of irradiation on bone and marrow phenotypes, and its relation to disruption of hematopoietic precursors. Bone 63: 87-94, 2014.

9. Coquard R: Late effects of ionizing radiations on the bone marrow. Cancer Radiother 1: 792-800, 1997.

10. Jia D, Gaddy D, Suva LJ and Corry PM: Rapid loss of bone mass and strength in mice after abdominal irradiation. Radiat Res 176: 624-635, 2011

11. Rodríguez JP, Astudillo P, Ríos S and Pino AM: Involvement of adipogenic potential of human bone marrow mesenchymal stem cells (MSCs) in osteoporosis. Curr Stem Cell Res Ther 3 208-218, 2008.

12. Asano S: Current status of hematopoietic stem cell transplantation for acute radiation syndromes. Int J Hematol 95: 227-231, 2012.

13. Shao L, Luo Y and Zhou D: Hematopoietic stem cell injury induced by ionizing radiation. Antioxid Redox Signal 20: 1447-1462, 2014.

14. Christensen DM, Iddins CJ and Sugarman SL: Ionizing radiation injuries and illnesses. Emerg Med Clin North Am 32: 245-265, 2014.

15. Heylmann D, Rödel F, Kindler T and Kaina B: Radiation sensitivity of human and murine peripheral blood lymphocytes, stem and progenitor cells. Biochim Biophys Acta 1846: 121-129, 2014.

16. Friedenstein A and Kuralesova AI: Osteogenic precursor cells of bone marrow in radiation chimeras. Transplantation 12: 99-108, 1971.

17. Zhang L, Peng LP, Wu N and Li LP: Development of bone marrow mesenchymal stem cell culture in vitro. Chin Med J (Engl) 125: 1650-1655, 2012.

18. Bidwell JP, Alvarez MB, Hood MJ and Childress P: Functional impairment of bone formation in the pathogenesis of osteoporosis: The bone marrow regenerative competence. Curr Osteoporos Rep 11: 117-125, 2013.

19. Bethel M, Chitteti BR, Srour EF and Kacena MA: The changing balance between osteoblastogenesis and adipogenesis in aging and its impact on hematopoiesis. Curr Osteoporos Rep 11: 99-106, 2013

20. James AW, Shen J and Khadarian K, Pang S, Chung G, Goyal R, Asatrian G, Velasco O, Kim J, Zhang X, et al: Lentiviral delivery of PPAR $\gamma$ shRNA alters the balance of osteogenesis and adipogenesis, improving bone microarchitecture. Tissue Eng Part A 20: 2699-2710, 2014.
21. Justesen J, Stenderup K, Ebbesen EN, Mosekilde L, Steiniche T and Kassem M: Adipocyte tissue volume in bone marrow is increased with aging and in patients with osteoporosis. Biogerontology 2: 165-171, 2001

22. Post S, Abdallah BM, Bentzon JF and Kassem M: Demonstration of the presence of independent pre-osteoblastic and pre-adipocytic cell populations in bone marrow-derived mesenchymal stem cells. Bone 43: 32-39, 2008

23. Gimble JM, Zvonic S, Floyd ZE, Kassem M and Nuttall ME: Playing with bone and fat. J Cell Biochem 98: 251-266, 2006.

24. Nicolay NH, Lopez PR, Debus J and Huber PE: Mesenchymal stem cells - A new hope for radiotherapy-induced tissue damage? Cancer Lett 366: 133-140, 2015.

25. Soleimani M and Nadri S: A protocol for isolation and culture of mesenchymal stem cells from mouse bone marrow. Nat Protoc 4: 102-106, 2009.

26. Qiu J, Zhu G, Chen X, Shao C and Gu S: Combined effects of $\gamma$-irradiation and cadmium exposures on osteoblasts in vitro. Environ Toxicol Pharmacol 33: 149-157, 2012.

27. Chen X, Zhu G, Gu S, Jin T, Shao C: Effects of cadmium on osteoblasts and osteoclasts in vitro. Environ Toxicol Pharmacol 28: 232-236, 2009.

28. Siclari VA, Zhu J, Akiyama K, Liu F, Zhang X, Chandra A, Nah HD, Shi S and Qin L: Mesenchymal progenitors residing close to the bone surface are functionally distinct from those in the central bone marrow. Bone 53: 575-586, 2013.

29. Wernle JD, Damron TA, Allen MJ and Mann KA: Local irradiation alters bone morphology and increases bone fragility in a mouse model J Biomech 43: 2738-2746, 2010.

30. Turner RT, Iwaniec UT, Wong CP, Lindenmaier LB, Wagner LA, Branscum AJ, Menn SA, Taylor J, Zhang Y, Wu H, et al: Acute exposure to high dose $\gamma$-radiation results in transient activation of bone lining cells. Bone 57: 164-173, 2013.

31. Tewarie RDSN, Hurtado A, Grotenhuis JA and Oudega M: Bone marrow stromal cell survival, migration, and differentiation following acute and delayed transplantation into the moderately contused adult rat thoracic spinal cord. Cell Res 18: S100, 2008.

32. Chen Q, Shou P, Zhang L, Xu C, Zheng C, Han Y, Li W, Huang Y, Zhang X, Shao C, et al: An osteopontin-integrin interaction plays a critical role in directing adipogenesis and osteogenesis by mesenchymal stem cells. Stem Cells 32: 327-337, 2014.

33. Cao X, Wu X, Frassica D, Yu B, Pang L, Xian L, Wan M, Lei W, Armour M, Tryggestad E, et al: Irradiation induces bone injury by damaging bone marrow microenvironment for stem cells. Proc Natl Acad Sci USA 108: 1609-1614, 2011

34. Gimble JM, Zvonic S, Floyd ZE, Kassem M and Nuttall ME: Playing with bone and fat. J Cell Biochem 98: 251-266, 2006.

35. Abdallah BM and Kassem M: New factors controlling the balance between osteoblastogenesis and adipogenesis. Bone 50: 540-545, 2012.

36. Agata H, Yamazaki M, Uehara M, Hori A, Sumita Y, Tojo A and Kagami H: Characteristic differences among osteogenic cell populations of rat bone marrow stromal cells isolated from untreated, hemolyzed or Ficoll-treated marrow. Cytotherapy 14: 791-801, 2012.

37. Hendry JH: The cellular basis of long-term marrow injury after irradiation. Radiother Oncol 3: 331-338, 1985.

38. Ashkenazi A and Dixit VM: Apoptosis control by death and decoy receptors. Curr Opin Cell Biol 11: 255-260, 1999.

39. Deng Y, Wu S, Zhou H, Bi X, Wang Y, Hu Y, Gu P and Fan X: Effects of a miR-31, Runx2, and Satb2 regulatory loop on the osteogenic differentiation of bone mesenchymal stem cells. Stem Cells Dev 22: 2278-2286, 2013.

40. Li J, Zhang N, Huang X, Xu J, Fernandes JC, Dai K and Zhang X: Dexamethasone shifts bone marrow stromal cells from osteoblasts to adipocytes by C/EBPalpha promoter methylation. Cell Death Dis 4: e832, 2013.

41. Viccica G, Francucci CM and Marcocci C: The role of PPAR $\gamma$ for the osteoblastic differentiation. J Endocrinol Invest 33 (Suppl): 9-12, 2010.

42. Justesen J, Stenderup K, Eriksen EF and Kassem M: Maintenance of osteoblastic and adipocytic differentiation potential with age and osteoporosis in human marrow stromal cell cultures. Calcif Tissue Int 71: 36-44, 2002. 